\title{
Development of Hypersensitivity Reactions After Using Different Oral Iron Preparations
}

\author{
Öner Özdemir ${ }^{1} \mathbb{D}$, Mustafa Büyükavcı²
}

Gastrointestinal side effects after using oral iron preparations have been usually observed, but skin reactions and allergic angioedema due to hypersensitivity have been rarely reported in the literature. We delineated 4 patients who were referred to us and who had shown hypersensitivity reactions following oral iron use, and their response to alternate oral iron preparations was evaluated. Initially prick and intradermal skin tests, and then oral provocations, were algorithmically performed in 4 patients to diagnose allergy to oral iron salts. Two of 4 cases showed hypersensitivity reactions after oral provocation. We were able to prevent the possible allergic reaction, which probably depends on IgE-mediated hypersensitivity, by simply changing the initial oral iron preparation to alternate one.

Keywords: Iron, allergy, hypersensitivity, anaphylaxis

This study was presented at LX. National Pediatrics Congress of Turkey, 9-13 November, Antalya, Turkey and XXIII. National Allergy and Clinic Immunolgy Congress of Turkey, 8-12 October, Muğla, Turkey.

ORCID IDs of all authors: 0̈.0̈. 0000-0002-53389561; M.B. 0000-0002-9054-3134

${ }^{1}$ Department of Pediatric Allergy-Immunolgy, Sakarya University Training and Research Hospital, Sakarya, Turkey ${ }^{2}$ Department of Pediatrics Hematology-Oncology, Sakarya University Training and Research Hospital, Sakarya, Turkey

Address for Correspondence: Öner Özdemir E-mail: oner.ozdemir.md@gmail.com

Received: 16.07.2017 Accepted: 06.11.2017

(C) Copyright 2018 by Available online at istanbulmedicaljournal.org

\section{Introduction}

Iron deficiency anemia (IDA) is the most important cause of infancy and childhood anemia worldwide (1). If anemia in childhood is particularly severe and extended, its effects on behavioral and psychomotor development may not fully regress despite treatment (2). For this reason, IDA has been included in the childhood screening program in our country, and oral iron preparations are started for all infants after 4 months. Oral ferric [iron (III)] and ferrous [iron (II)] preparations are used in the treatment and prophylaxis of iron deficiency. Parenteral preparations are administered to individuals with malabsorption. Hypersensitivity reactions, including anaphylaxis, have been frequently reported in parenteral/intravenous iron preparations, particularly those containing dextran $(3,4)$. Although gastrointestinal side effects (nausea, epigastric pain, constipation, etc.) are frequently reported after the use of oral preparations containing iron salts, hypersensitivityrelated skin reactions (maculopapular erythema, pustular rash, photodermatitis, etc.) and allergic angioedema have been rarely reported (5-10).

Allergy to iron itself has been rarely reported in intravenous and oral iron preparations; however, allergies to supplemental (sweetener and adjuvant) additives are more frequently observed $(6,8$, 11). Hypersensitivity can occasionally develop against ferrous iron content, ferric iron content, or against both. Ferrous or ferric preparations can also cross-react within themselves and between each other; for example, iron preparations, such as ferrous sulfate, ferrous ascorbate, ferrous lactate, and ferrous fumarate, have been reported to have a cross-reaction within themselves (12). The IgE-related immunologic response developed due to drug use plays a role in the etiology of hypersensitivity reactions after the use of iron supplementation. Hypersensitivity or tolerance to iron preparations can be detected through skin tests and provocation tests $(6,11,12)$. Herein, we investigated hypersensitivity reactions developed after the use of oral iron preparations in four different patients who applied to our clinic, evaluated their responses to different oral preparations, and attempted to determine the approach to be followed in these patients.

\section{Cases}

\section{Case 1}

A 31-month-old female patient was admitted to the hospital with a diagnosis of IDA as well as a complaint of mild swelling and urticarial rash around the eyes and lips after the use of iron (II) glycine sulfate complex (Ferro sanol ${ }^{\circledR}$ ). The history of the patient and family did not have any feature; there was no history of drug allergy and use of iron preparation. After noting a negative result for the patient's skin test, when the same preparation was given under observation, the patient developed angioedema on the face. Subsequently, the preparation was changed and 
iron (III) hydroxide polymaltose (Ferrum Haussmann ${ }^{\circledR}$ ) suspension treatment was started. After increasing the dose, no allergic reaction was observed at follow-up.

\section{Case 2}

A 80-day premature male patient was admitted to the hospital for IDA prophylaxis due to erythema and occasional urticarial rash following the administration of the iron (III) hydroxide polymaltose complex (Vegaferon $\left.{ }^{\circledR}\right)$. There was no history of drug use and allergy except for the use of Devit3 drops. After noting a negative result for the patient's skin test, when widespread urticarial plaques were observed during repeated use of the same iron preparation, the preparation was changed. Iron (II) glycine sulfate complex (Ferro sanol ${ }^{\circledR}$ ) was started at increasing doses. No allergic reaction was observed at follow-up (Figure 2).

\section{Case 3}

Urticarial rash developed in a 13-month-old male patient after iron (III) hydroxide polymaltose (Ferrum Haussmann ${ }^{\circledR}$ ) suspension was started for IDA therapy. At 4 months of age, he devel-

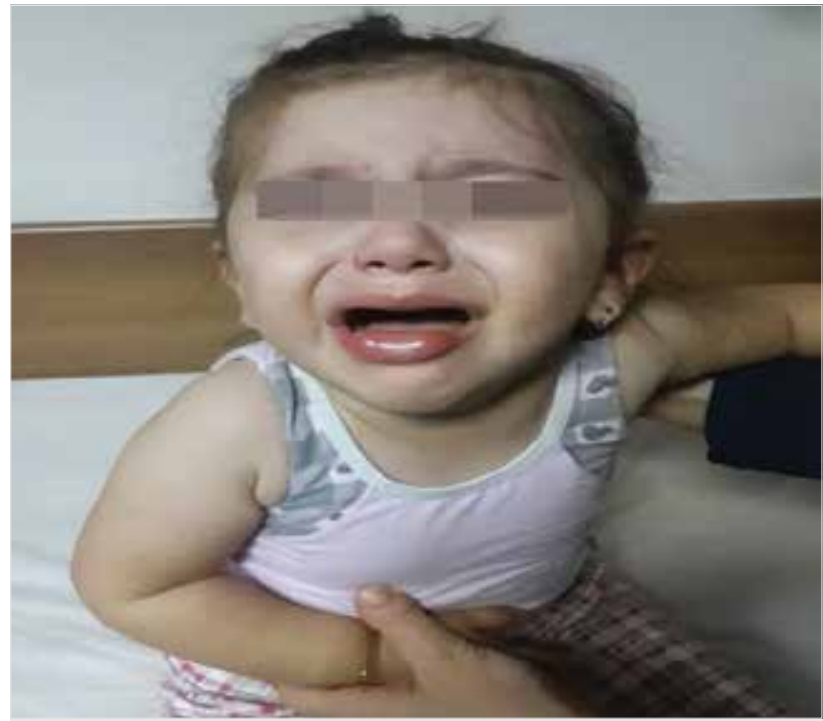

Figure 1. Angioedema developing on the lips of a girl after using an iron (II) glycine sulfate complex (Ferro sanol ${ }^{\circledR}$ ) syrup.

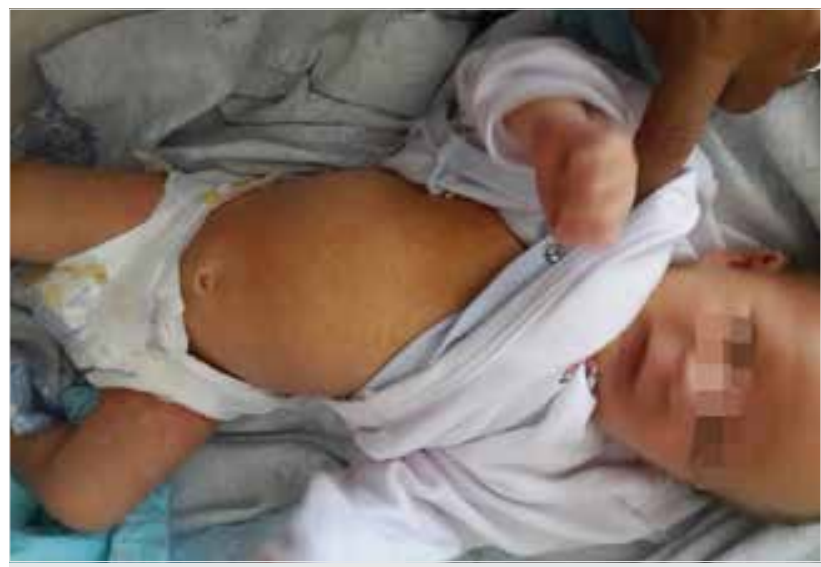

Figure 2. Erythematous rash on the skin following the use of iron (III) hydroxide polymaltose complex $\left(\right.$ Vegaferon $\left.^{\circledR}\right)$ drop. oped urticaria following the use of the drop form of the same iron preparation as a prophylaxis; therefore, the iron drop was not used again. Because the skin test was found to be negative for iron (II) glycine sulfate complex (Ferro sanol ${ }^{\circledR}$ ) syrup, which was planned to be used in the patient, no reaction was observed when he was given a provocation in increasing doses. No reaction was observed following the treatment.

\section{Case 4}

Iron (III) hydroxide polymaltose (Ferrum Haussmann ${ }^{\circledR}$ ) was started in a 12-year-old female patient after the diagnosis of IDA. After using the medicine, she presented with a complaint of mild angioedema occurring in the lips, face, and eyes. Negative results were noted for the skin and provocation tests with the same medicine, and no reaction was observed at increasing doses under observation. Subsequently, we decided to continue with the same medicine in the patient who had no features in her history as well as family history. No problems were reported at subsequent outpatient follow-ups, and IDA therapy was completed with the same medicine.

\section{Discussion}

Iron salts have a low molecular weight and are recognized by the immune system by binding to high-molecular-weight molecules. Ferric iron salts have the most stable form and bind to other macromolecules to a lesser extent, thus they are less allergenic. It is also known that ferric forms are less absorbable than ferrous forms, which may contribute to lesser allergic reactions (11-13). In contrast to findings in the literature, reaction was observed in three of our four patients with two different ferric preparations.

In order to diagnose early-type hypersensitivity reactions to iron preparations, we algorithmically subjected our patients to prick and intradermal skin tests and oral provocation. In our cases, the prick test was conducted using iron preparations at a dose of $10 \mathrm{mg} / \mathrm{mL}$, whereas the intradermal test was conducted using iron preparations at doses of $0.01 \mathrm{mg} / \mathrm{mL}$ and $0.1 \mathrm{mg} / \mathrm{mL}$ with the medicine itself consisting of oral ferrous or ferric iron preparations, which were considered to be replaced with it. Oral provocation tests were performed after noting negative results in the skin tests. Provocation was attempted with ferrous and ferric preparations at doses of $20 \mathrm{mg}$ (5 mg elemental iron), $100 \mathrm{mg}$ ( $25 \mathrm{mg}$ elemental iron), and $250 \mathrm{mg}$ (50 mg elemental iron) with 30-min intervals (14). After the results of skin and provocation tests showed that the medicine caused hypersensitivity in two of our patients, provocation was performed with an alternative medicine, after which it was safely used. Because the reaction was observed twice with the same medicine, considering the tests could be risky in the third case; thus, provocation was performed and no hypersensitivity reaction was observed. In the fourth case, despite the complaint, the same medicine was found to be safe after the tests and its use was continued.

In iron preparations, hypersensitivity reactions against iron itself as well as against several dyes (Sunset yellow, Sunflower yellow, etc.) have been reported, which are excipient substances in their contents (8). In our study, the contents of the iron preparations were administered to our patients according to the current drug guidelines (Vade mecum) and different websites as follows: Vegaferon ${ }^{\circledR}$ drop: iron (III) hydroxide polymaltose, saccharose, meth- 
ylparaben, propylparaben, cream essence, sodium hydroxide; Ferrum Haussmann ${ }^{\circledR}$ syrup: iron (III) hydroxide polymaltose, sugar, sorbitol, Nipagin M, Nipasol, cream essence R22, sodium hydroxide; and Ferro sanol ${ }^{\circledR}$ drop: iron glycol (ferrous) sulfate, sorbitol, saccharin, sulfuric acid, orange essence (ethanol).

The cream essence, sodium hydroxide, and sorbitol were common components of the iron preparations used in our cases. Dextran is considered to be responsible for inducing hypersensitivity reactions due to intravenous iron preparation $(3,4,11,13)$. Although there is no data related to oral preparations, we think that our patients may have developed these reactions due to the use of any of the above three components. Although a hypersensitivity reaction was not confirmed in the fourth patient, it had developed in three of our patients following the intake of oral iron preparation. We did not have the opportunity to test with the excipients (additives). However, the fact that there was no problem in the iron preparations with varying content and strength mainly suggested this result.

In the case of an allergic reaction to iron preparations, desensitization protocols may have to be used $(6,15,16)$. However, owing to the tolerance developed toward oral iron preparations and the reaction developed even in 4 days as Ortega et al. (17) reported, the treatment dose could occasionally not be achieved; in De Barrio et al.'s study, the treatment dose was achieved in 18 days and rapid desensitization was not possible (6). Several-hour desensitization protocols for parenteral preparations have been described by Rodríguez-Jiménez et al. (10). This is why parenteral desensitization is preferred for allergic reactions to oral preparation. Antihistamines, corticosteroids, and montelukast and occasionally even acetylsalicylic acid have been reported to be used before desensitization $(3,11,14-18)$. There was no need for risky and prolonged desensitization in preparations with varying content and strength in any of our cases.

When selecting alternate oral iron preparations for our patients, we paid attention to the iron strength of the preparation content and difference of excipient and dye substances, which helped in eliminating the hypersensitive reaction in our patients. Iron (III) preparation was changed to iron (II) preparation in two cases, and iron (II) preparation was changed to iron (III) preparation in one case; these alternate preparations could be safely applied. Our findings were consistent with those of current literature. When an allergy to ferrous preparations was reported in a study from Turkey, it was also shown that the ferric preparation could be tolerated (12).

In conclusion, by altering the type of oral iron preparation, we prevented allergic reactions depending on the IgE-mediated hypersensitivity mechanism, which we observed with different oral iron preparations used for IDA prophylaxis and treatment in different patients by evaluating the severity of the anemia and the necessity of treatment preparation. The preferred preparations with practically different contents should be tried before desensitization, and then an appropriate treatment approach should be determined.

Informed Consent: Verbal informed consent was obtained from parents of the patiens' who participated in this study.

Peer-review: Externally peer-reviewed.

Author contributions: Concept - Ö.Ö., MB; Design - Ö.Ö., M.B.; Supervision - Ö.Ö., M.B.; Resource - Ö.Ö.; Materials - Ö.Ö.; Data Collection and/ or Processing - Ö.0̈.; Analysis and/or Interpretation - Ö.Ö., M.B.; Literature Search - Ö.Ö.; Writing - Ö.Ö.; Critical Reviews - M.B.

Conflict of Interest: The authors have no conflict of interest to declare.

Financial Disclosure: The authors declared that this study has received no financial support.

\section{References}

1. Panagiotou JP, Douros K. Clinicolaboratory findings and treatment of iron-deficiency anemia in childhood. Pediatr Hematol Oncol 2004; 21: 521-34. [CrossRef]

2. de Andraca I, Castillo M, Walter T. Psychomotor development and behavior in iron-deficient anemic infants. Nutr Rev 1997; 55:125-32. [CrossRef]

3. Morales Mateluna CA, Scherer Hofmeier K, Bircher AJ. Approach to hypersensitivity reactions from intravenous iron preparations. Allergy 2017; 72: 827-30. [CrossRef]

4. Bailie GR, Clark JA, Lane CE, Lane PL. Hypersensitivity reactions and deaths associated with intravenous iron preparations. Nephrol Dial Transplant 2005; 20: 1443-9. [CrossRef]

5. Choulis NH, Dukes MNG. Metals. In: Dukes MNG and Aronson JK, eds. Meyler's side effects of drugs. Amsterdam: Elsevier, 2000; 683-713.

6. de Barrio M, Fuentes V, Tornero P, Sánchez I, Zubeldia J, Herrero T. Anaphylaxis to oral iron salts. desensitization protocol for tolerance induction. J Investig Allergol Clin Immunol 2008; 18: 305-8.

7. Kawada A, Hiruma M, Noguchi H, Kimura M, Ishibashi A, Banba H, et al. Photosensitivity due to sodium ferrous citrate. Contact Dermatitis 1996; 34: 77. [CrossRef]

8. Rogkakou A, Guerra L, Scordamaglia A, Canonica GW, Passalacqua G. Severe skin reaction due to excipients of an oral iron treatment. Allergy 2007; 62: 334-5. [CrossRef]

9. Ito A, Nomura K, Hashimoto I. Pustular drug eruption induced by ferrous fumarate. Dermatology 1996; 192: 294-5. [CrossRef]

10. Rodríguez-Jiménez B, Domínguez-Ortega J, Nu-ez-Acevedo B, CavaSumner B, Kindelan-Recarte C, Montojo-Guillén C. Rapid iron desensitization after generalized urticaria and facial angioedema. J Investig Allergol Clin Immunol 2014; 24: 69-71.

11. Rampton D, Folkersen J, Fishbane S, Hedenus M, Howaldt S, Locatelli $\mathrm{F}$, et al. Hypersensitivity reactions to intravenous iron: guidance for risk minimization and management. Haematologica 2014; 99: 16716. [CrossRef]

12. Yilmaz O, Erkasar Citak F. A case report with hypersensitivity to ferrous but tolerance of ferric iron salts. J Allergy Clin Immunol Pract 2016; 4: 343-4. [CrossRef]

13. Fletes R, Lazarus JM, Gage J, Chertow GM. Suspected iron dextranrelated adverse drug events in hemodialysis patients. Am J Kidney Dis 2001; 37: 743-9. [CrossRef]

14. Celik GE. İlaç aşııı duyarlıık reaksiyonlarına yaklaşım. Ulusal rehber. Ankara: Bilimsel Tıp Yayınevi; 2014.

15. Alam MG, Krause MW, Shah SV. Parenteral iron therapy: beyond anaphylaxis. Kidney Int 2004; 66:457-8. [CrossRef]

16. Monaghan MS, Glasco G, St John G, Bradsher RW, Olsen KM. Safe administration of iron dextran to a patient who reacted to the test dose. South Med J 1994; 87: 1010-2. [CrossRef]

17. Ortega N, Castillo R, Blanco C, Alvarez M, Carrillo T. Oral iron cutaneous adverse reaction and successful desensitization. Ann Allergy Asthma Immunol 2000; 84: 43-5. [CrossRef]

18. Demir S, Olgac M, Unal D, Gelincik A, Colakoglu B, Buyukozturk S. A practical and successful desensitization protocol for immediate hypersensitivity reactions to iron salts. Int Arch Allergy Immunol 2014; 165: 100-3. [CrossRef]

Cite this article as: Özdemir 0̈, Büyükavcı M. Development of Hypersensitivity Reactions after Using Different Oral Iron Preparations. İstanbul Med J 2018; 19: 173-5. 